\title{
ТЕРМИНОСИСТЕМА ИСКУССТВОВЕДЕНИЯ: ШИРОКОЗНАЧНОСТЬ И МНОГОЗНАЧНОСТЬ В ДЕЙСТВИИ
}

\author{
С. В. Иванова, П. Е. Гапиенко \\ Ленинградский государственный университет имени А. С. Пуикина
THE TERMINOLOGICAL SYSTEM OF ART HISTORY: EURYSEMY AND POLYSEMY IN ACTION

\author{
S. V. Ivanova, P. E. Gapienko \\ Pushkin Leningrad State University
}

\begin{abstract}
Аннотация: наблюдения над тенденциями развития и спецификой функционирования терминологии искусствоведения позволяют ставить проблему ее деструктуризации, что может быть связано с проявлениями широкозначности и многозначности. Актуальность настоящего исследования заключается 8 обращуении к одной из острых проблем современного терминоведения-разграничению широкозначности и многозначности и в освещуении особенностей их реализации в искусствоведческой терминологии. Цель данной работы состочт в определении специфики проявления эврисемии и полисемии в терминосистеме искусствоведения. Поставленная иель продиктовала необходимость использования дефиниционного анализа, онома- и семасиологического анализа, а также контекстуального анализа. В результате вылвлены общие черты многозначности и широкозначности в искусствоведческой терминологии: многозначные и широкозначные термины могут функционировать как в терминосистеме искусствоведения, так и в других научных терминосистемах, а также в общелитературном языке. Зачастую абстрактность и широкая градация значения, наряду с более широкой сферой применения эврисемичных терминов (за пределами искусствоведения) приводит к детерминологизации широкозначных терминов. Поскольку часть ключевых понятий искусствоведения в настоящее время десемантизированы, структуру искусствоведческой терминосистемы можно признать отчасти нарушенной. Развитие многозначности искусствоведческих терминов, напротив, обогащает искусствоведческую терминологию, а также свидетельствует об эволючии искусствоведения как научной дисциплины. Термины, многозначные на междисциплинарном уровне, приобретают свое уникальное значение в искусствоведческой терминологии. Со временем семантический объем полисемичных терминов искусствоведения дополняется новыми денотатами, характерными только для искусствоведческой терминосистемы. Таким образом, широкозначность и многозначность оказывают прямо противоположное влияние на искусствоведческую терминосистему: широкозначные термины дестабилизируют иерархию искусствоведческой терминосистемы, в то время как многозначные термины приводят кее развитию и подчеркивают самобытность искусствоведческого языка для специальных иелей.
\end{abstract}

Ключевые слова: полисемия, многозначность, эврисемия, широкозначность, искусствоведческая терминология, термин, детерминологизация.

\begin{abstract}
Art History terminology has led to the problem of destructuring the Art History terminology. The relevance of this research lies in the appeal to modern problems of terminology, i. e. the distinction between everysemy and polysemy in Art History terminology. The purpose of this work is to determine the specificity of everysemy and polysemy in the Art History terminology system. In the article, the features of broad meaning and polysemy in Art History terminology are considered for the first time. The methods employed in this work include definitional analysis, onoma- and semasiological analyses, as well as contextual analysis. As a result of this study, common features of
\end{abstract}

(C) Иванова С. В., Гапиенко П. Е., 2021

Контент доступен под лицензией Creative Commons Attribution 4.0 License.

The content is available under Creative Commons Attribution 4.0 License. 
polysemy and broad meaning in Art History terminology are identified: polysemous and broad-meaning terms can function both in the terminology system of Art History and in other scientific terminology systems, and even in the general literary language. Often, the abstract character and a wide gradation of meaning, as well as the wide scope of the use of everysemic terms (beyond Art History) often lead to the determination of broad-meaning terms. Since many of the key concepts of Art History are currently devoid of their full meaning, the structure of the Art-Historical terminology system can be called partially destructurized. The development of the polysemy of Art History terms, on the contrary, enriches Art History terminology, and also testifies to the evolution of Art History as a scientific discipline. Terms that are ambiguous at the interdisciplinary level in Art History terminology acquire their unique meaning. Over time, the semantic volume of polysemous terms of Art History is supplemented by new denotations that are applicable only in Art History terminology. Thus, broad-meaning and polysemy have a directly opposite effect on the Art History terminology system: everysemic terms destabilize the hierarchy of the Art History term system, while polysemic terms lead to its development and emphasize the originality of the Art History language for special purposes.

Key words: polysemy, ambiguity, everysemy, broad lexical meaning, Art History terminology, term, determinologization.

\section{Введение: постановка цели, методология, материал исследования}

Наблюдение и работа с терминологией искусствоведения неизбежно подводит исследователя к анализу проявления широкозначности и многозначности в рамках данной терминосистемы. В настоящее время с определенной долей смелости можно говорить о проблеме некоторой неупорядоченности терминологии искусствоведения, чему отчасти способствует развитие в ее пределах данных явлений. При этом многозначность (полисемия) предполагает «наличие у слова более чем одного значения» [1, с. 149], а широкозначность (эврисемия) в общем смысле «рассматривается как некая неопределенная многозначность» [2, с. 123] или «разновидность лексической семантики высокой степени обобщения, объединяющей слова с широкой понятийной основой» [3, с. 35]. Цель настоящего исследования состоит в установлении специфики реализации широкозначности и многозначности в терминосистеме искусствоведения. Заявленная цель обусловливает постановку ряда аналитико-исследовательских задач. Прежде всего необходимо разграничить термины «широкозначность» и «многозначность». Далее следует выявить источники названных явлений в терминосистеме искусствоведения и, наконец, установить потенциальные угрозы, которые несут многозначность и широкозначность для целостности современной искусствоведческой терминосистемы.

Для достижения цели и решения обозначенных выше задач в исследовании задействованы методы семантического анализа, которые включают дефиниционный анализ (применяется для определения действующего значения термина), онома- и семасиологический анализ (используется при установлении отношений между референтом/денотатом, понятием и языковым знаком), а также контекстуальный анализ (для выявления узуальной специфики). Материал исследования почерпнут из ряда словарей, включая The Concise Oxford Dictionary of Art Terms (2 ed.) [4],
The Oxford Dictionary of Art and Artists (5 ed.) [5]; Cambridge Dictionary [6], Encyclopedia of Aesthetics (2 ed.) [7], World Encyclopedia [8]. Выбор лексикографических источников для сбора эмпирических данных продиктован пониманием того, что «на пути от семантики к понятиям словарь может послужить источником научных концепций или средством их корректировки» [9, с. 318].

Исследование предварялось гипотезой: лингвистическая многозначность способствует развитию искусствоведческой терминологии без вреда для ее терминосистемы, в то время как широкозначность грозит размыванием структуры искусствоведческой терминосистемы, а также десемантизацией терминов, в том числе относящихся к ядру искусствоведческой терминосистемы.

\section{Проблема многозначности и широкозначности в современной семасиологии}

Многозначность и широкозначность имеют длительную и богатую традицию исследований в современной семасиологии $[2 ; 3 ; 10-19]$. Семасиологи подчеркивают, что если многозначное слово представляет собой системную взаимосвязь лексико-семантических вариантов [20, с. 72$]$, то широкозначное слово само по себе однозначно. Из всего перечня значений многозначного слова в контексте задействовано одно, в то время как в зависимости от контекста одно единственное значение широкозначного слова может трактоваться по-разному. Соответственно, широкозначное слово требует уточнения в контексте по причине пространного понятийного объема, широкой семантической референции, а также способности соотноситься с разными объектами мысли $[18$, c. 7].

В действительности различия между многозначностью и широкозначностью отличаются сложностью и неоднозначностью, о чем свидетельствует большой диапазон подходов к трактовке как самих этих явлений и, соответственно, понятий, так и их взаимосвя- 
зи: от придания широкозначности статуса разновидности полисемии с широким денотативным спектром, где у всех оттенков значения один семантический стержень [2, с. 123], который создает своего рода «гравитационное поле со сгущениями масс и тесным их взаимодействием» [9, с. 176], - до признания широкозначности отдельной лексико-семантической категорией [21, с. 104]. Среди множества дискуссионных мнений на широкозначность нельзя не упомянуть точку зрения Д. Н. Шмелева, касающуюся слов с «общим лексическим значением». Оговариваясь, что таким значением обладают лишь немногие лексические единицы [22, с. 95], он соотносит общее значение «с разнородными группами предметов на основе общего признака, который составляет основное семантическое содержание самого слова и который не закреплен в языке как сигнализирующий только об одной группе предметов, обладающих данным признаком» [там же, с. 95-96]. Следствием наличия такой широкой понятийной основы может выступать полная десемантизация [18, с. 8].

Согласно В. Г. Гаку, в результате десемантизации слова исчезает связь между словом и референтом, что приводит к утрате сем в структуре лексического значения [23, с. 325]. Соответственно, слово (или в данном случае термин) превращается в элемент внешней формы единицы другого уровня (классическим примером подобного рода могут служить сочетания существительного с предлогом, которые переходят в класс наречий). В то же время развитие широкозначности свидетельствует о способности к семантическому варьированию, поэтому широкозначные слова могут как терять, так и приобретать семы в зависимости от контекста $[15$, с. 16]. Тем не менее не все лингвисты согласны с фактом десемантизации широкозначных лексических единиц: даже повышение уровня абстрактности широкозначных лексем или утрата некоторых сем, включая основное значение слова, еще не являются причиной их десемантизации [12]. Ярким примером этого являются эквивалентные лексические единицы английского, немецкого и русского языков thing / Das Ding / вещъ. Несмотря на наличие широкого спектра значений, эти слова все же сохраняют «признак предметности независимо от контекста» [18, с. 8].

Применительно к искусствоведческой терминологии можно предположить, что развитие широкозначности и многозначности терминологии данной научной дисциплины является следствием абстрактного характера большинства терминов искусствоведения [24, с. 105], а также особенностей их взаимодействия с терминосистемами других областей научного знания.

Для того чтобы определить специфику бытования и функционирования широкозначных и многозначных терминов в профессиональной сфере искусствоведения, необходимо обратиться к анализу терминов, которые зафиксированы в искусствоведческих словарях английского языка. Сопоставление словарных дефиниций с реальным употреблением широкозначных и многозначных терминов искусствоведения позволит выявить особенности их функциональной семантики.

\section{Бытование широкозначных терминов в терминологии искусствоведения}

В результате анализа терминов терминологических единиц искусствоведения в [5] обнаружился довольно интересный факт: такие широкозначные лексические единицы, как art, school, style и др., согласно приведенному словарю не включены в состав терминов, несмотря на то что эти понятия в искусствоведении можно отнести к ключевым. Термин school, можно, тем не менее, найти в [4]. При этом обращает на себя внимание дефиниция данной лексемы «used to describe a group of artists working under the influence of a single master or sharing common characteristics because they come from a particular region or town, or practise the same local style» (используется для описания группь художников, работающзих под влиянием одного мастера или обладающчих общими характеристиками, поскольку они родом из определенного региона или города или практикуют один и тот же местный стиль) ${ }^{1}$. Совершенно очевидно, что в приведенной дефиниции заложена основа потенциальной детерминологизации данного термина - отсутствие конкретного денотата. Вместе с тем school продолжает функционировать в искусствоведческой терминологии, как правило, в составе названия творческих объединений, например, School of London, School of Paris [5]. Лексические единицы art, style of также упомянуты в [4] в качестве терминов искусствоведения, при этом они обозначают еще более абстрактные понятия. Следует отметить, что [4] издан в 2010 г., в то время как [5] вышел в свет в 2015 г. Таким образом, на наших глазах производится ревизия терминосистемы искусствоведения и часть единиц лишаются права претендовать на наличие терминологического статуса.

В этом отношении весьма примечательно, что в [5] указаны термины, обозначающие названия металлов: bronze (бронза), lead (свинеи), steel (сталь), несмотря на то что данные термины не являются исключительно искусствоведческими, и уж тем более они не входят в состав ядерных терминов искусствоведческой терминосистемы. Этот пример еще раз доказывает, что утрата терминологического статуса лексическими единицами, обозначающими основные

1 Здесь и далее перевод наш - С. И., П. Г. 
понятия искусствоведения, действительно требует внимательного рассмотрения.

Для решения выявленного противоречия следует обратиться к причинам детерминологизации терминов. Одной из причин детерминологизации функциональных терминов искусствоведения может послужить то обстоятельство, что термины искусствоведения употребляются в художественном и публицистическом текстах, где по воле авторов они замещают ненаучные наименования в угоду индивидуальному авторскому стилю. Даже если искусствоведческие термины, использованные в подобных текстах, сохранили те же денотаты, что в пределах терминосистемы искусствоведения, дистанция между термином и нетермином заметно сокращается. Безусловно, обыгрывание термина и его внутренней формы ставит под удар его терминологическую строгость. Данный процесс особенно опасен для широкозначных терминов искусствоведения, обозначающих абстрактные понятия. Поскольку слишком абстрактное, размытое и неопределенное значение многих эврисемичных терминов приводит к утрате четко выраженного лексического значения, ряд ученых даже связывают эврисемичность с десемантизацией $[18$, с. 8$]$. В этом отношении нельзя не сослаться на классическое понимание термина, которое характерно для концепции А. А. Реформатского: у термина должна быть ограниченная сфера функционирования, поскольку термин обозначает специальное понятие [25]. Если функционирование термина не ограничено рамками научной терминосистемы и он свободно употребляется в общелитературном языке, то, как отмечает А. В. Лемов, при размывании понятийной характеристики термин может «потерять терминологическую строгость» или превратиться в «просто элемент лексики научного стиля» [26], как это в итоге и произошло с названными выше art, school, style.

Данное наблюдение не является свидетельством того, что все широкозначные термины искусствоведения десемантизируются. Так, термин caricature вплоть до настоящего времени сохраняет свой терминологический статус и в [5] упоминается как «a form of art, usually portraiture, in which characteristic features of the subject represented are distorted or exaggerated for comic effect or to make critical comment. The term is sometimes used more broadly to denote other forms of pictorial burlesque or ludicrous representation, such as the grotesque heads of Leonardo...» (форма искусства, обычно портретная, в которой характерные черты изображаемого объекта искажаются или преувеличиваются для комического эффекта или для критического комментария. Этот термин иногда используется в более широком смысле для обозначения других форм живописного бурлеска или нелепого изображения, таких как гротескные головы Леонардо...).
Согласно приведенному определению, термин caricature относится скорее к живописи. Нередко при употреблении данного термина в текстах искусствоведческой направленности упоминается сам автор карикатур и особенности его стиля: «internationally acclaimed for his sharply conceived, finely drawn caricatures, Levine is one of the most influential caricaturists of the late twentieth century» (Левин, получивиий международное признание благодаря своим остроумным, тонко нарисованным карикатурам, является одним из самых влиятельных карикатуристов конца двадцуатого века) [27].

Если рассматривать сферу применения понятия карикатуры как таковой, то данная лексическая единица может использоваться в общелитературном языке со значением 'наглядная иллюстрация': «іn literature, a caricature is a character who is given a combination of oversimplified and exaggerated characteristics and features. While the type of caricatures that are popular as street art or political cartoons only highlight physical features, caricature examples in literature can often include personality features that are oversimplified or exaggerated» (в литературе карикатура это персонаж, которому дано сочетание упрощенных и преувеличенных характеристик и черт. В то время как карикатуры, которые популярны как уличное искусство или политические карикатуры, подчеркивают только физические особенности, примеры карикатур в литературе часто могут включать в себя черты характера, которые чрезмерно упрощуень или преувеличень) [28]. И если в литературоведческих словарях, изданных в Oxford University Press, caricature отказано в терминологическом статусе, искусствоведческие словари $[7 ; 8]$ содержат соответствующую вокабулу. Таким образом, есть все основания заключить, что данный термин все же тяготеет к функционированию в сфере искусствоведения.

Таким образом, не все широкозначные термины можно отнести к десемантизированным терминологическим единицам искусствоведческой терминологии. Однако следует учитывать, что чем больше степень абстрактности, граничащая с отсутствием денотата, тем выше вероятность детерминологизации эврисемичных терминов искусствоведения.

\section{Особенности развития многозначных терминов в сфере их функционирования}

Эволюция лексических единиц в пределах конкретной терминосистемы может протекать по-разному. Так, некоторые прежде широкозначные лексические единицы закрепились в терминологии искусствоведения, эволюционировав в многозначные термины. Среди них слово, которое функционирует как в общенаучной терминологии, так и в общелите- 
ратурном языке - donor. Согласно словарной дефиниции в [5] данную лексическую единицу можно определить как «a term applied to a person who commissions and pays for a work of religious art and has his or her portrait incorporated in it as an act of devotion. By having themselves included in the picture, donors sought to associate themselves in a special way with the sacred figures portrayed there, either in thanks for favours received or in the hope of future protection and salvation...» (термин, применяемый к человеку, который заказывает и оплачивает произведение религиозного искусства, за что его или ее портрет включен в него в качестве акта религиозного рвения. Будучи включенныли в изображение, донаторы стремились особым образом ассочиировать себя с запечатленнылми в нем священными фигурами, либо в знак благодарности за покровительство, либо в надежде на защиту и спасение в будущем...). В общем смысле, за пределами искусствоведческой терминологии слово donor понимается как человек, отдающий что-то другому человеку-рецепиенту [6], что означает, что как в толковом, так и в специализированном терминологическом словарях лексические значения данных лексем соотносятся между собой. Однако в [5] настоящий термин приобрел сугубо искусствоведческое значение, применение которого ограничено соответствующей сферой: «many devotional diptychs (two-panel paintings) such as this were painted in 15th-century Flanders. They consist of a portrait of the "donor" - or patron - in one panel, reverently gazing at the Madonna and Child in the other» (Много религиозньх диптихов (картины, состоящие из двух панелей), подобных этому, было написано во Фландрии XV в. Они состоят из портрета «донатора» - покровителя - на одной панели, с благоговением взирающего на Мадонну с младенцем на другой) [29]. Данный термин закрепился в искусствоведении в период эпохи Возрождения, когда многочисленные меценаты жертвовали значительные денежные средства, покровительствуя искусству, с одной стороны, и для увековечивания себя в произведения искусства - с другой. Специфичность данного вида пожертвований привела к возникновению на базе лексической единицы общелитературного языка уникального термина для искусствоведческой терминосистемы. Можно предположить, что в данном случае реализовалось новое значение, которое развилось на основе широкозначной лексической единицы, эволюционировавшей в языке для специальных целей в новую лексему, со временем закрепившуюся как термин средневекового искусства.

В искусствоведческой терминологии широкозначность и многозначность термина порою не имеют четко очерченных границ. Некоторые лексические единицы искусствоведения указаны в соответствую- щих терминологических словарях как термины, имеющие более одного значения. В качестве примера можно привести известный, в том числе за пределами искусствоведения, термин installation - «a term that can be applied very generally to the disposition of objects in an exhibition (the hanging of paintings, the arrangement of sculptures, and so on), but which also has the more specific meaning of a one-off work (often a largescale assemblage) conceived for and usually more or less filling a specific interior (generally that of a gallery)...» (термин, который может применяться в самом общем смысле к расположению объектов на выставке (развешивание картин, расстановка скульптур и m. д.), но также имеет более конкретное значение единоразовой работы (часто крупномасштабной сборки), которая задумана и обычно более или менее заполняет определенный интерьер (как правило, галереи)) [5]. Очевидно, что настоящий термин прежде всего понимается как способ размещения экспонатов при подготовке к открытию выставки, чему свидетельствует следующий пример: between the two of us, we've worked on at least 10 exhibition installations out of the Division of Political History, and no two have been quite alike. The basis of each installation is the same, but each has its own unique set of circumstances (Mь вдвоем работали по крайней мере над 10 выставочными инсталляциями из Отдела политической истории, $u$ не было двух абсолютно одинаковых. Основа всех установок одна, но у каждой из них есть свой уникальный набор обстоятельств) [30].

Исходя из данной дефиниции, без наличия каких-либо уточняющих терминов можно ошибочно заключить, что второе определение - лишь конкретизация первого значения. Однако в современном искусствоведении второе значение получило самостоятельность и понимается как новый жанр современного искусства, и в том числе упоминается в современных толковых словарях английского языка как "a form of modern sculpture where the artist uses sound, movement, or space as well as objects I order to make an often temporary work of art» (форма современной скульптуры, в которой художник использует звук, движение или пространство, а также объекты, чтобы создать временное произведение искусства) [6]. В некоторых источниках installation даже выделяют как отдельный жанр современного искусства: installation art is an artistic genre of three-dimensional works that often are site-specific and designed to transform the perception of a space. Generally, the term is applied to interior spaces, whereas exterior interventions are often called public art, land art or intervention art; however, the boundaries between these terms overlap (искусство инсталляции - это художественный жанр трехмерных работ, которые часто привязаны $\kappa$ конкретному месту и предназначены для 
преобразования восприятия пространства. Как правило, этот термин применяется к внутренним пространствам, тогда как внешние вмешательства часто называют паблик-артом, лэнд-артом или искусством вмешательства; однако границы между этими терминами частично совпадают) [31]. Вышеприведенный пример не только доказывает многозначность термина installation, но и свидетельствует о развитии значения: от инсталляции арт-объекта до инсталляции как самостоятельного жанра в искусстве.

Даже несмотря на то, что многозначные термины включены в состав терминов в специализированных словарях, ряд ведущих специалистов в области терминоведения [25, с. $61 ; 32$, с. $36 ; 33$, с. 199] придерживаются мнения, что термины должны быть однозначными. По всей видимости, ученые связывают однозначность с точностью и конкретностью значения, что является категориальным признаком термина. Однако, как уже было упомянуто выше, многозначность является результатом как эволюции научного языка, так и закрепившегося в обиходе метафорического творчества. Многие иностранные исследователи также называют многозначность естественным свойством термина. Так, согласно С. Ульману, многозначность необходима языку - без нее пришлось быть держать в памяти чрезмерно большой запас слов. Ученый назвал многозначность универсальным наследием фундаментальной структуры языка [34, p. 232]. Так, согласно статистическим данным, в английском языке свыше 40 \% слов имеют более одного значения [35]. Понятие «полисемия» настолько укоренилось в английском языке, что более желательная для научной терминологии «моносемия» определяется как «отсутствие полисемии»: «polysemy is a marked property of a word's semantic value, worthy of a special term and special attention. As perhaps not the least important indication of this markedness, the complementary term monosemy, cf.'lack of polysemy', is a less frequent term mainly devised for the purposes of polysemy research as a negative counterpoint» (многозначность - это ярко выраженное свойство семантики слова, заслуживающее особого термина и особого внимания. Возможно, не менее важный показатель этой отмеченности, дополнительный термин моносемия, ср. «отсутствие многозначности», является менее частым термином, в основном разработанным в целях исследования многозначности в качестве отрицательного противовеса) [36]. Кроме того, многозначные термины, как это было установлено в ходе исследования словарных единиц, могут означать специальные понятия искусствоведения и поэтому имеют право на существование в терминосистеме данной научной дисциплины.
Следовательно, широкозначность и многозначность естественны для англоязычной терминологии, но по-разному отражаются на состоянии искусствоведческой терминосистемы. В результате своего развития широкозначные термины способны детерминологизироваться, что может привести к образованию «пустот» в структуре искусствоведческой терминосистемы, вплоть до выхода ядерных терминов из состава терминосистемы. Развитие широкозначности также может привести к непропорциональности статуса терминологической единицы и ее места в терминосистеме, когда второстепенное по важности в терминосистеме слово приобретает статус термина, а ключевое понятие научной дисциплины теряет свой терминологический статус. В результате можно констатировать, что широкозначность несет определенную угрозу строгости иерархии и самой организации искусствоведческой терминосистемы. В свою очередь, многозначность способствует развитию терминосистемы без вреда для последней.

\section{Выводы}

Несмотря на такие общие свойства многозначных и широкозначных терминов искусствоведения, как способность многих из них одновременно бытовать в общелитературном языке и в других областях гуманитарного знания (особенно в терминосистеме литературоведения), специфика каждого из данных явлений по-разному отражается на терминосистеме искусствоведения. Многозначные термины, как и широкозначные, функционируют в общелитературном языке, но с заметным отличием от эврисемичных терминов. Параллельное функционирование полисемичных терминов как в бытовой лексике, так и в языке для специальных целей не убавляет степени их терминологичности в искусствоведческой терминосистеме, поскольку многозначный термин нередко употребляется в специальном, научном значении, неприменимом за пределами искусствоведческой терминосистемы. Помимо этого, в процессе своего развития многозначные термины искусствоведения способны приобретать новые денотаты. Более того, функционирующие в искусствоведческой терминологии многозначные термины со временем могут способствовать появлению новых терминологических единиц, образованных на базе оригинального многозначного термина. Широкозначные термины, характеризующиеся семантической многоплановостью, будут сохранять при этом единственное значение, причем по семантическому объему оно в основном будет совпадать с лексической единицей общелитературного языка (что не должно быть свойственно термину как единице языка для специальных целей). Кроме того, отсутствие денотата, абстрактность значения, характерные для многих эврисемичных тер- 
минов, также ставят под вопрос их терминологических статус. По этой причине многие широкозначные термины, включающие даже понятия, относящиеся к ядру искусствоведческой терминосистемы, подвергаются десемантизации, что не может не приводить к дестабилизации искусствоведческой терминосистемы. Следовательно, есть все основания полагать, что бо́льшую опасность для структуры искусствоведческой терминосистемы могут представлять именно широкозначные термины, в то время как многозначные термины в пределах искусствоведческой терминосистемы демонстрируют способность к обогащению своего семантического объема, и, в целом, укоренению в терминосистеме, сохраняя при этом свою уникальность в рамках искусствоведческой терминологии.

\section{Заключение}

Искусствоведческий термин представляет собой весьма любопытное явление с точки зрения терминоведения: порою он кажется «простым» и потому очевидным с точки зрения профанного реципиента. Однако необходимо помнить, что за кажущейся поверхностной понятностью скрывается сложная специальная область профессиональных знаний, с одной стороны. С другой стороны, в системе языковых знаков, обслуживающих данную область специальных знаний, проходят непростые семантические процессы, большое место среди которых занимают трансформации, связанные с проявлениями широкозначности и многозначности. Как показывает анализ, и полисемия, и эврисемия, наряду с другими факторами и явлениями, влекут за собой целый ряд процессов, которые могут как стабилизировать, так и дестабилизировать терминосистему искусствоведения, в связи с чем неизменность ее границ перестает быть константой.

\section{ЛИТЕРАТУРА}

1. Кронгауз М. А. Семантика. М. : Рос. гос. гуманит. ун-т, 2001. 399 с.

2. Малютина Е. И. Широкозначность против полисемии на уровне языка и речи (на материале глаголов современного английского языка) // Известия Российского государственного педагогического университета им. А. И. Герцена. 2007. № 37. С. 123-128.

3. Желонкина Т. П. О широкозначности прилагательных в современном английском языке // Вестник БФУ им. И. Канта. 2014. № 2. С. 35-42.

4. The Concise Oxford Dictionary of Art Terms (2 ed.). URL: https://www.oxfordreference.com/view/10.1093/ acref/9780199569922.001.0001/acref-9780199569922

5. The Oxford dictionary of Art and Artists (5 ed.). URL: https://www.oxfordreference.com

6. Cambridge Dictionary. URL: http://dictionary.cambridge.org/
7. Encyclopedia of Aesthetics (2 ed.). URL: https:// www.oxfordreference.com/view/10.1093/acref/97801 99747108.001.0001/acref-9780199747108-e-131?rskey= 4S6dlG\&result $=6$

8. World Encyclopedia. URL: https:/www.oxfordreference.com/view/10.1093/acref/9780199546091.001.0001/ acref-9780199546091-e-2019?rskey=4S6dlG\&result=1

9. Никитин М. В. Курс лингвистической семантики. СПб. : Изд-во РГПУ им. А. И. Герцена, 2007. 819 с.

10. Амосова Н. Н. Основы английской фразеологии. Л. : Ленинград. гос. ун-т им. Жданова, 1963. 208 с.

11. Уфимиева А. А. Типы словесных знаков. М. : Наука, 1974. $206 \mathrm{c}$

12. Плоткин В. Я., Гросул Л. Я. Широкозначность как лексико-семантическая категория // Теоретические проблемы семантики и ее отражения в одноязычных словарях. Кишинев : Штиинца, 1982. С. 81-86.

13. Феоктистова Н. В. Формирование семантической структуры отвлеченного имени (на материале древнеанглийского языка). Л., 1984. 142 с.

14. Аралов А. М. О проблеме отбора и месте широкозначных слов в структуре частей речи // Социолингвистические и лингвистические аспекты в изучении иностранных языков. М. : Ун-т Дружбы народов, 1992. C. $23-31$.

15. Авдеев A. A. Проблема широкозначности и ее соотношение с полисемией и дейксисом (на материале имен существительных английского, русского и французского языков) : дис. ... канд. филол. наук. Воронеж, 2002. $198 \mathrm{c}$.

16. Архипов И. К. Новые тенденции анализа лексической полисемии // Вестник Моск. гос. лингв. ун-та. 2008. № 544. C. 23-32.

17. Федосова О. В. Глаголы широкого значения в испанском обиходном дискурсе // Филологические науки. Вопросы теории и практики. Тамбов, 2010. № 1 (5), ч. I. C. 218-221.

18. Панкина М. Ф. Широкозначность и полисемия // Научный вестник Воронеж. гос. архит.-строит. ин-та. Сер.: Лингвистика и межкультурная коммуникация. 2013. № 10. С. 7-12.

19. Литвинова Н. В. Семантический потенциал широкозначного глагола «ДЕЛАТЬ» в языках различных групп // Изв. Сарат. ун-та. Нов. сер. Сер. Филология. Журналистика. 2016. Т. 16, вып. 4. С. 371-375.

20. Беляевская Е. Г. Семантика слова. М. : Высшая школа, 1987. $128 \mathrm{c}$.

21. Луговой В. С. К трактовке явления широкозначности слова и фразеологической единицы // Проблемы романистики. М., 1991. Вып. 2. С. 94-104.

22. Шмелев Д. Н. Очерки по семасиологии русского языка. М. : Едиториал УРСС, 2003. 244 с.

23. Гак В. Г. Языковые преобразования. М. : Языки русской культуры, 1998. 768 с.

24. Анисимова А. Г. Методология отбора терминов при обучении языку для специальных целей // Известия высших учебных заведений. Поволжский регион. Гуманитарные науки. 2011. № 2 (18). С. 98-108. 
25. Реформатский А. А. Введение в языковедение / под ред. В. А. Виноградова. М. : Аспект Пресс, 1996. $536 \mathrm{c.}$

26. Лемов A. В. Система, структура и функционирование научного термина (на материале русской лингвистической терминологии) : автореф. дис. ... д-ра филол. наук. Саранск, 2000. 32 c.

27. Cartoon America. Revelation. From A Magic Pen: Caricature. URL: https://www.loc.gov/exhibits/cartoonamerica/cartoon-caricature.html

28. Bloodless Genocide. A Political History of the Pitcairn People in Norfolk Island from 1856 to 1996. URL: https://www.pitcairners.org/bloodless_genocide2. html

29. Devotional. Art genre. URL: https://www.britannica.com/art/devotional

30. 10 things to know about exhibition installation. URL: https://americanhistory.si.edu/blog/10-things-exhibition-installation

31. Installation art. URL: https://www.hisour.com/installation-art-21337/

32. Гринев-Гриневич С. В. Терминоведение. М. : Академия, 2008. 304 с.

33. Лейчик B. М. Терминоведение : предмет, методы, структура. М. : Изд-во ЛКИ, 2007. 256 с.

34. Ullman S. The Principles of Semantics. Oxford : Basil Blackwell, 1967. 352 p.

35. Durkin K., Manning J. Polysemy and the Subjective Lexicon : Semantic Relatedness and the Salience of Intraword Meanings // Journal of Psycholinguistic Research. 1989. № 18. Pp. 577-612.

36. Raucco $J$. The status of polysemy in linguistics : from discrete meanings to default flexibility // SKY 1997 : The 1997 Yearbook of the Linguistic Association of Finland, 1997. Pp. 145-170.

\section{REFERENCES}

1. Krongauz M. A. Semantika [Semantics]. M.: Ros. gos. gumanit. un-t, 2001. 399 p.

2. Malyutina E. I. Shirokoznachnost' protiv polisemii na urovne yazyka i rechi (na materiale glagolov sovremennogo angliyskogo yazyka) [Broad meaning against polysemy at the level of language and speech (based on the verbs of modern English)]. In: Izvestiya Rossiyskogo gosudarstvennogo pedagogicheskogo universiteta im. A. I. Gertsena. 2007. Issue. 37. Pp. 123-128.

3. Zhelonkina T. P. O shirokoznachnosti prilagatel'nykh $v$ sovremennom angliyskom yazyke [On the broad-valuedness of adjectives in modern English]. In: Vestnik BFU im. I. Kanta. 2014. Issue 02. Pp. 35-42.

4. The Concise Oxford Dictionary of Art Terms (2ed.). Available at: https://www.oxfordreference.com/view/ 10.1093/acref/9780199569922.001.0001/acref-9780199 569922

5. The Oxford dictionary of Art and Artists (5 ed.). Available at: https://www.oxfordreference.com

6. Cambridge Dictionary. Availavle at: http://dictionary. cambridge.org/
7. Encyclopedia of Aesthetics (2 ed.). Available at: https://www.oxfordreference.com/view/10.1093/ acref/9780199747108.001.0001/acref-9780199747108-e131 ? rskey $=4$ S6 dlG\&result $=6$

8. World Encyclopedia. Available at: https://www.oxfordreference.com/view/10.1093/acref/9780199546091. 001.0001/acref-9780199546091-e-2019?rskey=4S6dlG\&result $=1$

9. Nikitin M. V. Kurs lingvisticheskoj semantiki [The course of linguistic semantics]. SPb.: Izd-vo RGPU im. A. I. Gercena, 2007. 819 p.

10. Amosova N. N. Osnovy anglijskoj frazeologii [Fundamentals of English phraseology]. L.: Len. gos. un-t im. Zhdanova, 1963. 208 p.

11. Ufimceva A. A. Tipy slovesnyh znakov [Types of word signs]. Moscow: Nauka, 1974. 206 p.

12. Plotkin V. Ja., Grosul L. Ja. Shirokoznachnost' kak leksiko-semanticheskaja kategorija [Broad meaning as a lexical-semantic category]. In: Teoreticheskie problemy semantiki $i$ ee otrazhenija $v$ odnojazychnyh slovarjah. Kishinev: Shtiinca, 1982. Pp. 81-86.

13. Feoktistova N. V. Formirovaniye semanticheskoy struktury otvlechennogo imeni (na materiale drevneangliyskogo yazyka) [Formation of the semantic structure of an abstract name (based on the material of the Old English language)]. L., 1984. 142 p.

14. Aralov A. M. O probleme otbora I meste shirokoznachnyh slov v strukture chastej rechi [On the problem of selection of the place of wide-valued words in the structure of parts of speech]. In: Sociolingvisticheskie i lingvisticheskie aspekty v izuchenii inostrannyh jazykov. Moscow: Un-t Druzhby narodov, 1992. Pp. 23-31.

15. Avdeev A. A. Problema shirokoznachnosti i ee sootnoshenie s polisemiej i dejksisom (na materiale imen sushhestvitel'nyh anglijskogo, russkogoi francuzskogo jazykov) [The problem of broad meaning and its relationship with polysemy and deixis (based on nouns in English, Russian and French): PhD Dissertation. Voronezh. gos. un-t. Voronezh, 2002. 198 p.

16. Arkhipov I. K. Novyye tendentsii analiza leksicheskoy polisemii [New trends in the analysis of lexical polysemy]. In: Vestnik Moskovskogo gosudarstvennogo lingvisticheskogo universiteta. 2008. No. 544. Pp. 23-32.

17. Fedosova O. V. Glagoly shirokogo znacheniya $v$ ispanskom obikhodnom diskurse [Broad meaning verbs in everyday Spanish discourse]. In: Filologicheskiye nauki. Voprosy teorii i praktiki. Tambov: Gramota, 2010. No. 1 (5). Part I. Pp. 218-221.

18. Pankina M. F. Shirokoznachnost' i polisemija [Broad meaning and polysemy]. In: Nauchnyy vestnik Voronezhskogo gosudarstvennogo arkhitekturno-stroitel'nogo instituta. Seriya Lingvistika i mezhkul'turnaya kommunikatsiya. 2013. No. 10. Pp. 7-12.

19. N. V. Litvinova. Semanticheskij potencial shirokoznachnogo glagola «DELAT'»v yazykah razlichnyh grupp [The Semantic Potential of the Verb with a Broad Meaning 'Do' in Languages of Different Groups]. In: Izv. Saratov. un-ta. Nov. ser. Ser. Filologiya. Zhurnalistika. 2016. Vol. 16. Issue 4. Pp. 371-375. 
20. Belyaevskaya E. G. Semantika slova [Semantics of the word]. M.: Higher School, 1987. 128 p.

21. Lugovoj V. S. K traktovke javlenija shirokoznachnosti slova i frazeologicheskoj edinicy [On the interpretation of the phenomenon of wide-meaning words and phraseological units]. In: Problemy romanistiki. Moscow, 1991. Issue 2. Pp. 94-104.

22. Shmelev D. N. Ocherki po semasiologii russkogo yazyka [Essays on the semasiology of the Russian language]. M.: Editorial URSS, 2003. 244 p.

23. Gak V. G. Yazykovyye preobrazovaniya [Language transformations]. M.: Yazyki russkoy kul'tury, 1998. $768 \mathrm{p}$.

24. Anisimova A. G. Metodologija otbora terminov pri obuchenii jazyku dlja special'nyh celej [Methodology for the selection of terms in teaching language for special purposes]. In: Izvestiya vysshikh uchebnykh zavedeniy. Povolzhskiy region. Gumanitarnyye nauki. 2011. No. 2 (18). Pp. 98-108.

25. Reformatskij A. A. Vvedenie v jazykovedenie [Introduction to linguistics]. Pod red. V. A. Vinogradova. Moscow: Aspekt Press, 1996. 536 p.

26. Lemov A. V. Sistema, struktura i funkcionirovanie nauchnogo termina (na materiale russkoj lingvisticheskoj terminologii) [System, structure and functioning of a scientific term (based on the material of Russian linguistic terminology)]. PhD Dissertation Abstract. Saransk, 2000. $32 \mathrm{p}$.

Ленинградский государственный университет имени А. С. Пушкина

Иванова С. В., доктор филологических наук, профессор, заведующая кафедрой романо-германской филологии и лингводидактики

E-mail: svet_victoria@mail.ru

Гапиенко П. Е., аспирант кафедры романо-германской филологии и лингводидактики

E-mail: polina.gapienko@mail.ru

Поступила в редакциюю 15 августа 2021 2.

Принята к публикаџии 15 октября 2021 г.

\section{Для цитирования:}

Иванова С. В., Гапиенко П. Е. Терминосистема искусствоведения: широкозначность и многозначность в действии // Вестник Воронежского государственного университета. Серия: Лингвистика и межкультурная коммуникация. 2021. № 4. C. 38-46. DOI: https://doi. org/10.17308/lic.2021.4/3809
27. Cartoon America. Revelation. From A Magic Pen: Caricature. Available at: https://www.loc.gov/exhibits/cartoonamerica/cartoon-caricature.html

28. Bloodless Genocide. A Political History of the Pitcairn People in Norfolk Island from 1856 to 1996. Available at: https://www.pitcairners.org/bloodless_genocide2.html

29. Devotional. Art genre. Available at: https://www. britannica.com/art/devotional

30. 10 things to know about exhibition installation. Available at: https://americanhistory.si.edu/blog/10-thingsexhibition-installation

31. Installation art. Available at: https://www.hisour. com/installation-art-21337/

32. Grinev-Grinevich S. V. Terminovedenie [Terminology. Tutorial]. Moscow: Akademija, 2008. 304 p.

33. Lejchik V. M. Terminovedenie: predmet, metody, sruktura [Terminology: subject, methods, structure]. Moscow: Izdatel'stvo LKI, 2007. 256 p.

34. Ullman S. The Principles of Semantics. Oxford: Basil Blackwell, 1967. 352 p.

35. Durkin K., Manning J. Polysemy and the Subjective Lexicon: Semantic Relatedness and the Salience of Intraword Meanings. In: Journal of Psycholinguistic Research. 1989. No. 18. Pp. 577-612.

36. Raucco J. The status of polysemy in linguistics: from discrete meanings to default flexibility. In: SKY 1997: The 1997 Yearbook of the Linguistic Association of Finland, 1997. Pp. 145-170.

\section{Pushkin Leningrad State University}

Ivanova S. V., Doctor of Philology, Professor, Head of the Romance and Germanic Philology and Linguodidactics Department

$$
\text { E-mail: svet_victoria@mail.ru }
$$

Gapienko P. E., Post-graduate Student of the Romance and Germanic Philology and Linguodidactics Department E-mail: polina.gapienko@mail.ru

Received: 15 August 2021

Accepted: 15 October 2021

\section{For citation:}

Ivanova S. V., Gapienko P. E. The terminological system of art history: eurysemy and polysemy in action. Proceedings of Voronezh State University. Series: Linguistics and Intercultural Communication. 2021. No. 4. Pp. 38-46. DOI: https://doi.org/10.17308/lic.2021.4/3809 